\title{
A IMPORTÂNCIA DA DIVULGAÇÃO DO CONHECIMENTO CIENTÍFICO PARA A PRÁTICA DA ENFERMAGEM CIRÚRGICA
}

DOI: 10.5327/Z1414-4425201600020001

0 s avanços tecnológicos e esforços científicos para divulgação do conhecimento que vem ocorrendo nas últimas décadas colocam os profissionais da saúde frente ao desafio de se manter continuamente atualizados. Para isto é necessário decidir, tanto de forma rápida e criteriosa quais artigos devem ser lidos como estar suficientemente treinados para fazer uma análise crítica da literatura. Muitas vezes nos perguntamos: quando uma pesquisa traz impacto para a prática e quando gera uma evidência científica?

Evidência científica se dá quando o resultado da pesquisa é fruto de delineamentos elaborados com rigor metodológico que minimiza as chances de "viés/bias", ou seja, um tipo de erro que, sistematicamente, distorce os resultados. A matéria-prima da evidência científica é a Epidemiologia Clínica, uma das ciências básicas que traz bases matemáticas e estatísticas associadas à prevenção de tendenciosidades que nos levam a resultados de pesquisa fundamentados em conclusões científicas básicas e confiáveis.

A tomada de decisão na área da saúde é bastante complexa e deveria ser adotada mediante identificação criteriosa da força e nível da evidência da pesquisa. Por exemplo, uma revisão sistemática com metanálise gera uma forte evidência, um ensaio clínico é considerado nível 1 de evidência, um estudo de coorte nível 2 e um estudo caso-controle nível 3. Somado a isto, a prática na área da saúde deveria ser sustentada por pesquisas que geram evidências.

A finalidade do consumo da pesquisa clínica de qualidade é fundamental para os profissionais da saúde porque dá alicerce forte para avaliar criticamente a prática em relação aos achados de pesquisa e promover mudanças baseadas em evidências. O grande desafio desta próxima década é formar e capacitar profissionais da área da saúde com discernimento para entender significância clínica e estatística, com competência quer para medir o impacto de uma pesquisa clínica, quer para saber se a intervenção proposta traz redução da morbimortalidade e melhoria na qualidade de vida dos pacientes atendidos em serviços de saúde ${ }^{1,2}$.

A Enfermagem de Centro Cirúrgico vivencia diuturnamente experiências que geram possibilidades de pesquisa e inúmeras perguntas ainda não respondidas. Encorajamos estes enfermeiros a se aproximarem das Universidades para serem orientados na condução da busca das respostas para seus questionamentos visando à possibilidade de gerar novos conhecimentos.

Desta forma, a Revista da Associação Brasileira de Enfermeiros de Centro Cirúrgico, Recuperação Anestésica e Centro de Material e Esterilização - Rev. SOBECC — inicia uma nova etapa de incentivo pela divulgação do conhecimento visando ao aprimoramento e atualização dos profissionais de enfermagem que prestam assistência ao paciente cirúrgico. A atual gestão editorial assume o desafio de divulgar pesquisas sustentadas por evidências que traga impacto para a área e que certamente trará benefícios no cuidado à saúde.

Esperamos que o esforço deste Conselho Editorial em colaborar com a divulgação do conhecimento da área possa ser uma ferramenta que contribua e suscite os especialistas a buscar evidências para intervir na prática com segurança.

Dulce Barbosa

Professora Associada, Livre Docente da Escola Paulista de Enfermagem da Universidade Federal de São Paulo - Unifesp São Paulo (SP), Brasil

Elena Bohomol

Professora Adjunta, Livre Docente da Escola Paulista de Enfermagem da Universidade Federal de São Paulo - UnifespSão Paulo (SP), Brasil

\section{REFERÊNCIAS}

1. Barbosa, DA. Importância da pesquisa clínica para a prática na área de saúde. Acta Paul Enferm. 2010;23(1):vii.
2. Barbosa D, Taminato M, Fram D, Belasco A. Enfermagem Baseada em Evidências. 1a ed. São Paulo-(SP): Atheneu; 2014. 